\title{
Nasjonalt register for leddproteser* Til beste for pasienter og det norske helsevesenet
}

\author{
Stein Atle Lie ${ }^{1}$, Stein Emil Vollset ${ }^{1}$, Ove Furnes ${ }^{2}$, Leif Ivar Havelin ${ }^{2}$, \\ Birgitte Espehaug $^{2}$ og Lars Birger Engesæter ${ }^{2}$ \\ 1) Seksjon for Epidemiologi og Medisinsk Statistikk, Institutt for Samfunnsmedisinske fag, \\ Universitetet i Bergen, 5018 Bergen \\ 2) Nasjonalt register for leddproteser, Ortopedisk klinikk, Haukeland Universitetssykehus, 5021 Bergen \\ Korrespondanse: Stein Atle Lie, Stein.Lie@smis.uib.no Telefon 55588522 Telefaks 55588520
}

\begin{abstract}
SAMMENDRAG
Bakgrunn: Norsk ortopedisk forening startet i 1987 hofteregisteret hvor alle operasjoner med innsetting av kunstige hofteledd, total hofteprotese, i Norge ble registrert. Registeret ble i 1994 utvidet til alle ledd. Hensikten med registeret var å oppdage dårlige proteser og prosedyrer så tidlig som mulig.

Materiale og metode: Alle de 70 norske sykehus hvor slike operasjoner utføres, og omlag 400 ortopediske kirurger, rapporterer til registeret. Protesene følges inntil eventuell reoperasjon for protesen eller til pasienten dør.

Resultat og fortolkning: Flere proteser og sementer, som benyttes for å feste protesen i beinet, med dårlig resultat er oppdaget tidlig og er ikke lenger i bruk. Både sementtypen Boneloc og lavviskøse sementer er fjernet fra markedet etter rapporter fra det norske leddproteseregisteret. Med økende alder i befolkningen og økende antall operasjoner hos yngre vil protesekirurgien i Norge øke i fremtiden. Manglende krav til klinisk dokumentasjon for nye leddproteser fører til at stadig nye proteser og sementer tas i bruk uten at vi kjenner deres langtids egenskaper. Det er derfor fortsatt viktig med et nasjonalt register som følger protesekirurgien.
\end{abstract}

Lie SA, Vollset SE, Furnes O, Havelin LI, Espehaug B, Engesæter LB. The Norwegian Arthroplasty Register: Beneficial for patients and for the Norwegian health care system. Nor J Epidemiol 2004; 14 (1): 57-63.

\section{ENGLISH SUMMARY}

Background: The Norwegian Orthopaedic Association started the Norwegian Arthroplasty Register in 1987. The register was extended to include arthroplasties in all joints in 1994. The aim of the registry was to detect inferior implants, cements and operation techniques as early as possible.

Material and methods: All 70 Norwegian hospitals where such operations are performed, and approximately 400 surgeons, report to the register. The prostheses are followed until a revision operation or to the patients dies.

Results: Several hip prostheses and cements with inferior results were detected early and are no longer in use. Both the cement type Boneloc and low viscosity cements are removed from the marked after reports from the Norwegian register. With an increasing age in the population and an increasing number of operations on younger patients, the number of prostheses operations, inserting an artificial joint, will increase in the future. Due to the lack of demands for clinical documentation, new products will be introduced to the marked without knowledge on its future qualities. The register will, therefore, continue to be important to survey short term results for new implants and also long term results for established implants.

* Denne artikkelen er en omarbeidet versjon av artikkelen: Furnes O, Havelin LI, Espehaug B, Engesæter LB, Lie SA, Vollset SE. Det norske leddproteseregisteret - 15 nyttige år for pasientene og for helsevesenet. Tidsskr Nor Lageforen 2003; 123 (10): $1367-9$.

På grunn av dårlige resultater med den norske Christiansen hofteprotesen og dobbeltkopp-proteser på 1970tallet og tidlig på 1980-tallet, og introduksjonen av mange nye udokumenterte kunstige hofteledd opprettet Norsk ortopedisk forening et nasjonalt register for hofteproteser. Registreringen av alle totale kunstige hofteledd (proteser) startet 15. september 1987.

Hensikten med registeret var å påvise dårlige resultat av hofteproteser så tidlig som mulig. Registeret er ikke opprettet for å avdekke hvilke prosedyrer og proteser som er best, fordi det da kunne bli en vurdering av marginale forskjeller samt at de fleste av disse pro- duktene kun benyttes av et fåtall kirurger og sykehus. Det har også vist seg at produkter kan være svært gode de første registreringsårene, men ikke ha gode resultater på lengre sikt. For å få kirurgene til å rapportere, ble registreringsskjemaet utformet så kortfattet som mulig. Pasientens fødselsnummer, operasjonsdato, diagnose, samt utfyllende informasjon om protesetype, som regel ved klistrelapp som følger med produktinnpakningen, og andre variabler relatert til operasjonen er plassert på et en sides skjema (1). Reoperasjon (fjerning og skifting av protesedeler) meldes på samme en sides skjema. 


\section{FAKTA}

- Leddprotesekirurgi i Norge er godt kvalitetssikret gjennom Nasjonalt Register for Leddproteser.

- Med økende alder i befolkningen og økende antall operasjoner hos yngre vil protesekirurgien i Norge $ø$ ke i fremtiden.

- Manglende krav til klinisk dokumentasjon for nye leddproteser fører til at stadig nye proteser og sementer tas i bruk uten at vi kjenner deres fremtidige egenskaper.

- Nasjonalt register for leddproteser har i løpet av sin eksistens vist seg å være avgjørende for å avdekke dårlige proteser og prosedyrer på et tidlig stadium.

- Registeret vil fortsette å spille en viktig rolle for å beskrive kvaliteten av protesekirurgi i Norge.

\section{NASJONALT REGISTER FOR LEDDPROTESER}

Oppmuntret av den gode oppslutningen (2) og resultatene fra de andre nordiske proteseregistrene, ønsket Norsk ortopedisk forening også å registrere andre leddproteser enn de som brukes i hofter. Fra 1994 har vi derfor registrert proteser $i$ andre ledd og registeret endret da navn til Nasjonalt register for leddproteser (3). Registeret inneholder nå informasjon om 92000 hofteproteser og 20000 andre leddproteser, rapportert fra alle 70 norske sykehus som utfører slik kirurgi. Mer enn 7000 hofteproteser og nesten 2500 kneproteser ble operert inn i 2002. Siden 1989 har det vært en økning i årlig rapporterte hofteproteser på 17\%, og siden 1994 på $123 \%$ for kneproteser, sammenlignet med 2002.

\section{ARBEIDSFORM}

Fra registeret utgis det årlig en rapport som sendes alle medlemmer av Norsk ortopedisk forening samt myndigheter og proteseleverandørene. I tillegg gis det ut en sykehusvis rapport som sendes til en kontaktperson ved hvert av de deltakende sykehus. I denne rapporten gis det deskriptive data samt proteseresultater for det aktuelle sykehus sammenliknet med gjennomsnittsresultater for hele landet og anonyme resultater for de øvrige sykehusene. I tillegg presenteres også resultater og vitenskapelige arbeider ved Norsk kirurgisk forenings høstmøte. Registerets medarbeidere har publisert over 30 vitenskapelige artikler de siste ti år og det er avlagt fire doktorgrader basert på data fra registeret. Det har hele tiden vært et viktig prinsipp ved leddproteseregisteret at registerets leger skal være aktive ortopediske kirurger, med nær kontakt til de kliniske fagmiljøer. Videre har det også blitt sett på som avgjørende med statistisk kompetanse knyttet nært til registeret. Denne bindingen mellom ortopeder og statistikere $\mathrm{i}$ registeret er blitt regnet som en viktig årsak til registerets suksess.

\section{RESUltater}

I tabell 1 gis det en oversikt over de viktigste funn fra registeret. Allerede etter 3 år kunne registeret legge frem resultater som dokumenterte at flere usementerte proteser gav dårlige resultater, spesielt hos unge personer (4). I 1991 ble Boneloc-sementen introdusert, og den oppnådde i løpet av 1-2 år en markedsandel på $14 \%$. Allerede etter 2,5 år kunne registeret påvise en øt revisjonsfrekvens for Boneloc-sement, og publisering av data fra registeret var sterkt medvirkende til at salget av denne sementen ble stoppet på verdensmarkedet (5). Registeret viste i 1995 at den lavviskøse sementen CMW III hadde dårligere resultat etter fem år enn høyviskøse sementer (5). Etter ti års oppfølging av sementer hadde også den høyviskøse sementen CMW I dårligere resultater enn andre sementer (6).

Vi har også vist at antibiotikaprofylakse sammen med antibiotikaholdig sement gav færrest revisjoner på grunn av infeksjon (7). Videre har vi kunnet vise at fire gjentatte doser med antibiotika operasjonsdagen gav mindre infeksjoner enn færre doser, og at det ikke er noen økt beskyttende effekt ved å gi profylaksen $\mathrm{i}$ to eller tre dager (8).

Den tilgrunnliggende hoftesykdommen betyr lite for resultatet av hofteproteser. Men det viser seg at svært mange pasienter med diagnoser hvor pasientene fikk hofteprotese i ung alder, hadde fått dårlige usementerte proteser (9).

Resultater fra registeret har raskt gitt en endring av praksis hos norske ortopeder. Figur 1 viser endring $\mathrm{i}$ bruk av Boneloc-sement og lavviskøs sement. Men istedenfor å gå over til veldokumenterte proteser og sementer etter slike erfaringer velger kirurgen ofte nye og udokumenterte proteser og sementer. Dette er mulig fordi kravene til klinisk dokumentasjon av proteser og sementer ikke er underlagt de samme krav til kliniske studier som medikamenter.

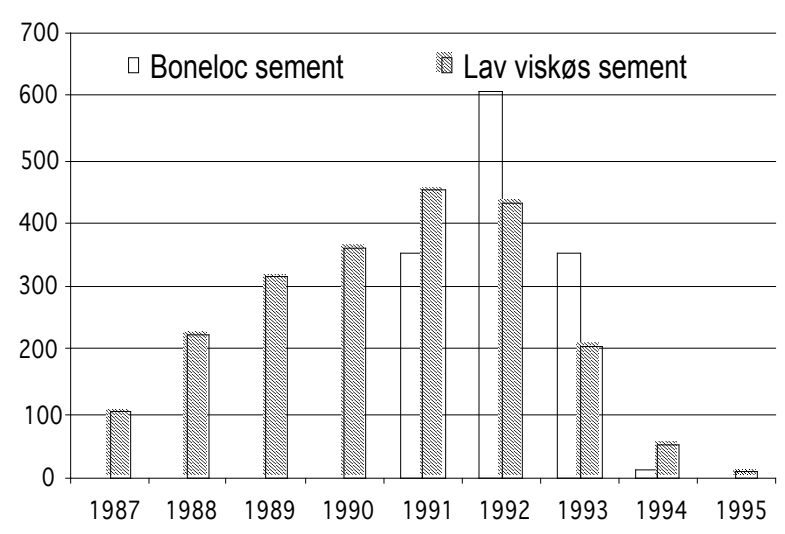

Figur 1. Endring i bruk av lavviskøse sementer og Bonelocsement etter at de dårlige resultatene ble kjent. 
Tabell 1. Oversikt over hovedfunn fra studier utgått fra Nasjonalt Register for Leddproteser 1987-2002.

Etter 3 års observasjonstid kunne registeret dokumentere dårlige resultat for Boneloc-sement (5) og for glatte, usementerte femur- og acetabularkomponenter $(21,22)$. Charnley protesen hadde dårligere resultat når den ble fiksert med den lavviskøse sementen CMW III sammenlignet med de høyviskøse sementene. Palacos og Simplex sement gav de beste resultater (5). Etter mer enn 10 års oppfølging viste det seg også at den høyviskøse sementen CMW I hadde dårligere resultat enn Palacos og Simplex sement (6).

Både Charnley og Exeter proteser hadde dårlig resultat ved bruk av Boneloc sement. Exeter lårbensprotese hadde lavere risiko for revisjon enn Charnley protesen ved bruk av denne sementen (23).

Antibiotikaprofylakse gitt som en kombinasjon av systemisk antibiotika og antibiotikaholdig sement var assosiert med færre revisjoner på grunn av infeksjon og aseptisk løsning enn når antibiotika bare ble gitt systemisk (7). Det ser ut til å være tilstrekkelig å gi antibiotikaprofylakse kun 1 dag, men det må da gis fire doser denne dagen (8).

Usementerte, hydroksyapatitt og sirkulært porøst belagte lårbensstammer hadde bedre resultat enn sementerte stammer ved 10 års oppfølging (24).

Usementerte, porøst belagte kopper hos unge pasienter hadde lavere revisjonsrate med aseptisk løsning som endepunkt enn sementerte kopper, men høyere revisjonsrisiko for alle revisjoner på grunn av slitasje av plast og osteolyse (24).

De usementerte hydroksyapatittbelagte koppene Tropic og Atoll hadde en høyere revisjonsrisiko på grunn av aseptisk løsning, slitasje og osteolyse enn de sementerte koppene (25).

Pasienter med intakt primærprotese hadde bedre funksjon og mindre smerte enn pasienter med revidert protese (26).

Det er funnet økt risiko for revisjon for hofteproteser hos unge pasienter sammenlignet med eldre pasienter og hos menn sammenlignet med kvinner (4).

Økt vekt, tidligere røykere, høyt alkoholinntak og medikamentforbruk på grunn av diabetes gav alle økt risiko for revisjon av hofteprotese. Det samme gjaldt pasienter som brukte systemisk eller lokale steroider og hos kvinner som hadde tungt arbeid (27).

Primære hofteproteser satt inn ved universitetssykehus hadde dårligere resultat enn proteser satt inn ved sentralog lokalsykehus, denne forskjellen skyldes delvis en mer utstrakt bruk av usementerte proteser med dårlig design ved universitetssykehusene. For usementerte hofteproteser var det en høyere risiko for revisjon ved sykehus som utførte mindre enn 10 usementerte hofteproteser per år (28).

Den tilgrunnliggende hoftesykdom hadde liten betydning for 10-års resultatene for primær hofteproteser, unntaket for dette var pasienter med totalluksert hofte etter hofteleddsdysplasi og pasienter som hadde fătt utført totalprotese $\mathrm{i}$ hofte på grunn av hoftefraktur $(9,29)$. Pasienter som hadde fătt protese i ung alder hadde ofte fått dårlige usementerte proteser (9).

Sementerte totalproteser i hoften hadde generelt gode resultater både etter 5 og 10 års oppfølging $(24,30)$.

Sementerte kneproteser hadde gode resultat etter 5 år. Kneproteser med patellakomponent hadde flere reoperasjoner på grunn av infeksjon enn kneproteser uten patellakomponent, men færre reoperasjoner for smerte (17).

Dødeligheten hos pasientene var økt de første 60 dager etter operasjon for totalprotese $\mathrm{i}$ hofte sammenliknet med gjennomsnittet $\mathrm{i}$ befolkningen, dette skyldes økt dødelighet på grunn av tromboembolisk sykdom og hjerte- og karsykdommer (12).

Tidlig postoperativ dødelighet økte med alder, var høyere hos menn enn kvinner og skyldtes vaskulær sykdom. Vi fant noe redusert dødelighet postoperativt i slutten av registreringsperioden (12).

Ved 10-års oppfølging hadde pasienter som hadde fått totalprotese i hofte lavere dødelighet enn normalbefolkningen. For pasienter under 60 år var derimot dødeligheten høyere enn i normalbefolkningen (11).

Endring i størrelsen på protesehodet (caput) fra 32 til $28 \mathrm{~mm}$ er assosiert med en øket risiko for at protesen lukserer (31).

Høy fysisk aktivitet på arbeid og høy kroppsmasseindeks gav økt risiko for å få hofteprotese senere i livet (13). En endring i kroppsmasseindeks ga ingen endring i risikoen for å få hofteprotese (14). 


\section{KOBLING TIL ANDRE REGISTRE}

Registeret samarbeider med Norsk pasientregister (NPR) om å undersøke hvor mange proteser som blir meldt til registeret. I en gjennomgang fra 1995 til 1997 viste det seg at registeret hadde fått rapportert opptil $2 \%$ flere totalproteser i hofte enn Norsk pasientregister. Det har også vært samarbeid med SINTEF Unimed for å beskrive fylkesvise variasjoner i bruk av primærprotese og revisjonskirurgi (10).

Årlig kobles leddproteseregisteret med opplysninger om avdøde personer fra det sentrale folkeregisteret. Denne koblingen er avgjørende for oppfølgingen av proteser og pasienter. Vanligvis er det tid til revisjon av leddprotesene som er det interessante endepunktet i studier fra registeret, men registeret har også sett på levetid for pasienter etter operasjon med innsetting av leddprotese $(11,12)$. Det er også foretatt en kobling til dødsårsaksregisteret ved Statistisk sentralbyrå for å studere dødsårsaker $\mathrm{i}$ den tidlige postoperative fasen etter innsetting av total hofteprotese (12).

Mulighet for kobling av data fra andre helseregistre er også utnyttet i form av samarbeid med Statens helseundersøkelser (SHUS), hvor man fant at økende kroppsmasseindeks gav økt risiko for senere å få hofteprotese (13), mens endring av kroppsmasseindeks ikke betydde noe for risikoen (14).

Leddproteseregisteret har samarbeidet med Riksrevisjonen om effektiviteten i sykehus. Data fra leddproteseregisteret og Norsk pasientregister ble benyttet for å studere ventetid og liggetid ved totalprotese $\mathrm{i}$ norske sykehus (15).

\section{MULIGE KOBLINGER TIL LEDDPROTESE- REGISTERET}

Det arbeides for tiden med et prosjekt der man ønsker å koble data fra Medisinsk fødselsregister med data fra leddproteseregisteret. Formålet med denne studien er å se om medfødte tilstander (for eksempel klinisk instabile hofter) kan gi en øket risiko for kunstig hofteledd i ung voksen alder. I Leddproteseregisteret er det om lag 450 personer med fødselsår senere enn 1967, som var oppstartåret for Medisinsk fødselsregister. Leddproteseregisteret er også med i Locus for registerepidemiologi ved Universitetet i Bergen, der blant annet også Medisinsk fødselsregister deltar.

Videre kan for eksempel en kobling mellom leddproteseregisteret og Kreftregisteret være en interessant mulighet, basert på at pasienter med leddproteser kan bli utsatt for påvirkning av de stoffer (metaller og plast) som en protese består av. Hvis disse stoffene gir en øket risiko for kreft kan det på den annen side være mulig at tid før kreft utvikler seg er så lang at det i praksis vil være vanskelig å måle en effekt. En slik kobling mellom et leddproteseregister og kreftregister er allerede foretatt i Finland (16).

\section{LEDDPROTESEREGISTRE I ANDRE NORDISKE LAND}

I Sverige ble register for kneproteser opprettet i 1975 i Lund, mens registeret for hofteproteser startet i 1979 i Gøteborg. Det svenske hofteproteseregisteret registrete fram til 1992 kun reoperasjonene med summariske opplysninger for de primære operasjonene, men etter 1992 har de innført personidentifiserbar registrering av samtlige operasjoner.

Det Finske hofteproteseregisteret ble startet i 1982 med en lovpålagt og personidentifiserbar registrering. De senere årene har både Danmark og Island fulgt etter med registre for hofteproteser.

En lang rekke land rundt $i$ verden har de siste årene opprettet eller arbeider med å opprette leddproteseregistre etter mønster fra det norske og de nordiske registre. Det arbeides også med å koordinere et europeisk hofteproteseregister, som tar utgangspunkt $i$ data fra de nasjonale registrene. Det norske registeret deltar $\mathrm{i}$ denne prosessen både med sin ekspertise og har også meldt sin interesse for å drive den sentrale databasen, som anslagsvis kan dekke 500000 totale hofteproteser per år.

\section{EFFEKT PÅ KVALITETEN AV PROTESE- KIRURGIEN}

Tabell 2 viser at kvaliteten på protesekirurgien målt med proteseoverleving er bedret $\mathrm{i}$ de siste tidsperiodene. Den relative risikoen for revisjon av en primær hofteprotese er redusert med 35\% $(\mathrm{p}<0,001)$ fra tidsperioden 1987-90 til 1997-1999. Vi kan se en kvalitetsreduksjon i perioden med Boneloc sement (1991-93) for sementerte proteser, men etter 1994 har resultatet for sementerte proteser bedret seg (figur 2). For usementerte proteser har det vært en jevn bedring av resultatene for alle tidsperioder (figur 3).

Tabell 2. Ujusterte risikoestimat for reoperasjon for alle primære totalproteser $(n=77809)$ i hoften for kategorier av kalendertid.

\begin{tabular}{|c|c|c|}
\hline Tidsperiode & Risk-ratio & $95 \%$ konfidensintervall \\
\hline $1987-1990$ & 1 & \\
\hline $1991-1993^{1}$ & 1,24 & $1,16-1,33$ \\
\hline 1994-1996 & 0,84 & $0,77-0,92$ \\
\hline 1997-1999 & 0,65 & $0,58-0,72$ \\
\hline
\end{tabular}

${ }^{1}$ Boneloc-sement ble brukt i denne perioden

Tall fra det svenske hofteregisteret som har vært i virksomhet siden 1978, kan tyde på at deres systematiske registreringsarbeid har høynet kvaliteten på svensk hofteprotesekirurgi, og at den er bedre enn for eksempel i USA og andre land uten slike registre. 


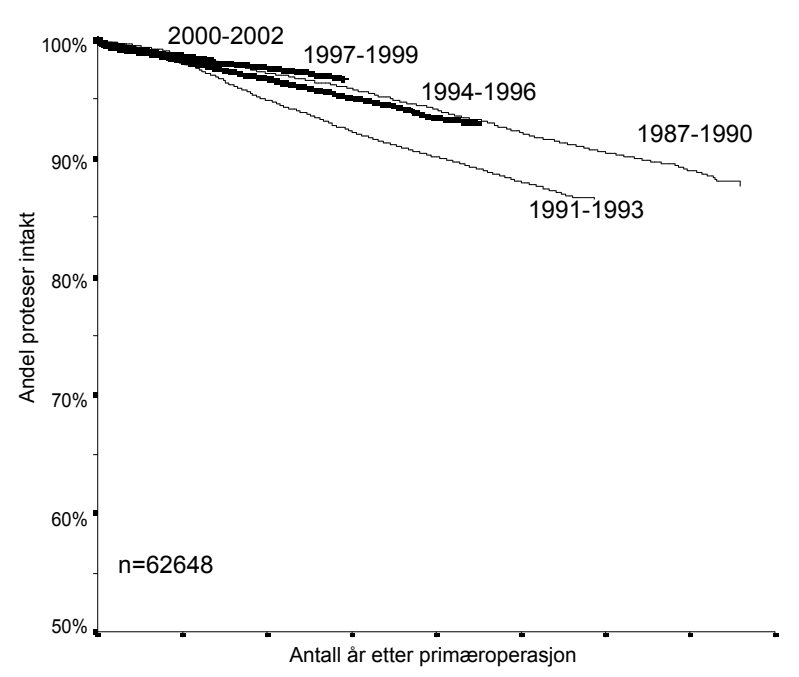

Figur 2. Andel intakte sementerte totale hofteproteser for ulike tidsperioder.

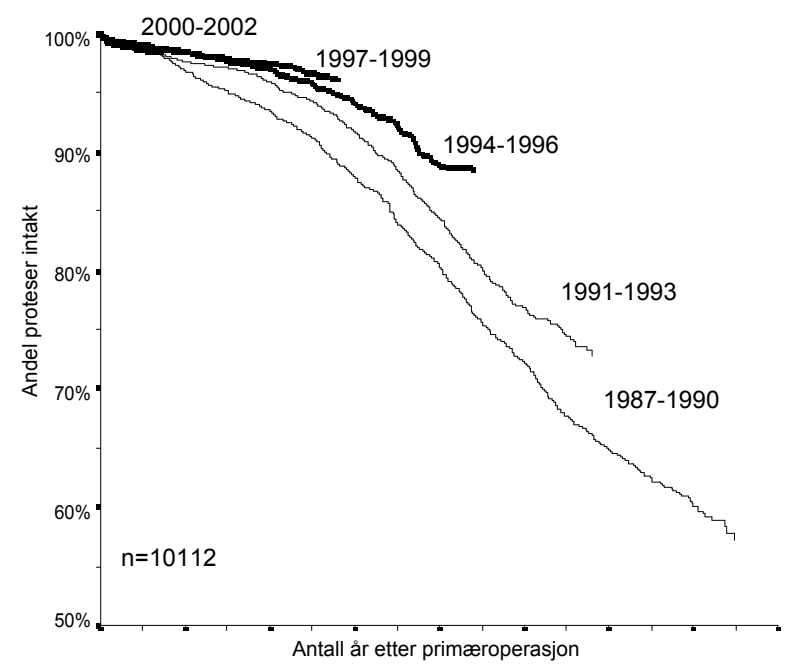

Figur 3. Andel intakte usementerte totale hofteproteser for ulike tidsperioder.

Kneprotesekirurgien har kortere observasjonstid, og det har ikke vært noen endring i resultater i den siste tidsperioden. For kneproteser var det færre implantattyper på markedet enn for hofteproteser, og kirurgene har vært mer konservative ved å satse på sementerte kneproteser. Revisjonsraten for kneproteser er 1-2\% lavere i Norge enn i Sverige (17). For hofteproteser har vi hatt noe høyere revisjonsrate enn $\mathrm{i}$ Sverige, trolig på grunn av et høyere antall usementerte proteser. Revisjonsprosenten i Norge er imidlertid lavere enn $i$ alle andre land med kjente tall for dette.

Registeret har i en studie av den tidlige postoperative dødelighet for pasienter etter hofteprotesekirurgi påvist en gradvis redusert dødelighet for de første 60 postoperative døgn i registreringsperioden (12).

\section{GOD SAMFUNNSøKONOMI}

Årlig representerer leddprotesekirurgien en DRG inntekt for norske sykehus på 1 milliard norske kroner. Leddproteseregisteret representerer en kvalitetssikring med en kostnad på kun kroner 160 per protese. Det vil si at kun $0,16 \%$ av kostnaden for protesekirurgien for den norske stat brukes til den kvalitetssikringen leddproteseregisteret representerer. Hver unngåtte reoperasjon sparer samfunnet for minst kr. $100000(18,19)$. Nedgang i andelen revisjoner i tabell 2 representerer titalls sparte millioner kroner per år.

\section{AnsatTe}

Registeret har 1 1/2 sekretærstilling, en statistikerstilling og en overlegestilling som deles på tre ortopediske kirurger. En post doc stipendiat og fire doktorgradskandidater arbeider for tiden med problemstillinger fra registeret. Fra 1. januar 2004 har registeret også blitt utvidet til å omfatte korsbåndsopererte. I forbindelse med dette er staben utvidet med 1/2 IT-stilling og 1/2 sekretærstilling.

\section{FINANSIERING}

Finansieringen var et problem fra starten. Arbeidet ble finansiert gjennom forskjellige fond, og mye av arbeidet har blitt gjort og gjøres fortsatt på fritiden. Fra 1992-96 var driften sikret ved tilskudd fra kvalitetssikringsfondet i Den norske lægeforening. Driftsbudsjettet dekkes nå av Helse Vest og Helse Bergen og for korsbåndsdelen via legeforeningens kvalitetssikringsfond og Senter for idrettskadeforskning ved Idrettshøyskolen.

\section{FREMTIDEN}

De siste 3-4 årene er det introdusert nye prinsipper for protesekirurgi som metall-mot-metall-artikulasjon, keramikk-mot-keramikk-artikulasjon og polyetylen fremstilt med nye metoder (highly cross-linked polyethylene). Det er fortsatt usikkerhet om hvilken metallegering som er best i proteser. Det diskuteres hvilken geometri og overflateruhet sementerte proteser bør ha. Flere av proteseprodusentene endrer sine produkter før langtidsresultater (>10 år) foreligger. Flere nye sementer er introdusert de siste tre år selv om det er kjent at endring i kjemisk sammensetning av sement kan gi uante problemer. $54 \%$ av de usementerte protesene som ble brukt på det norske marked i 2001 har mindre enn 4 års klinisk oppfølging (20). Tall fra Sverige tyder på at protesekirurgien vil øke med $30 \%$ de neste 20 årene bare på bakgrunn av en økende andel eldre $\mathrm{i}$ befolkningen, og da er ikke vår tendens til stadig å operere eldre, sykere og yngre pasienter medregnet. 
Det er derfor fortsatt viktig med et nasjonalt register som følger protesekirurgien. Sentralt for dette registeret er selvsagt at det jevnlig produserer vitenskapelige resultater for problemstillinger knyttet til leddproteser, og da ikke bare på leddproteseregisterets egne data, men også på data fra andre ressurser. Nasjonalt register for leddproteser har nylig fått status som Nasjonalt kompetansesenter for leddproteser. Det er også startet registrering av korsbåndoperasjoner i knær (anslagsvis 2000 per år) og det er planer om å starte registrering av lårhalsbrudd i løpet av 2005. Således vil det i framtiden være økende potensial for å belyse problemstillinger knyttet til hyppige ortopediskkirurgiske prosedyrer $\mathrm{i}$ framtiden, til beste for pasienter og det norske helsevesen.

Takk til de ortopediske kirurger og kontaktpersonene ved sykehusene for deres trofaste innrapportering til registeret.

\section{REFERANSER}

1. Havelin LI, Espehaug B, Vollset SE, Engesæter LB, Langeland N. The Norwegian Arthroplasty Register. A survey of 17,444 total hip replacements. Acta Orthop Scand 1993; 64: 245-51.

2. Engesæter LB, Havelin LI, Espehaug B, Vollset SE. Kunstige hofteledd i Norge. Tidsskr Nor Lageforen 1992; 112: 872-5.

3. Furnes A, Lie SA, Havelin LI, Engesæter LB. Kvalitetskontroll av proteseoperasjoner i kne, ankel-, tå-, skulder-, albue- og fingerledd i Norge 1994. En rapport etter det første året med registrering i Nasjonalt Register for Leddproteser. Tidsskr Nor Loegeforen 1996; 116: 1777-81.

4. Havelin LI, Espehaug B, Vollset SB, Engesæter LB. Early failures among 14,009 cemented and 1,326 uncemented prostheses for primary coxarthrosis. The Norwegian Arthroplasty Register, 1987-1992. Acta Orthop Scand 1994; 65: 1-6.

5. Havelin LI, Espehaug B, Vollset SE, Engesæter LB. The effect of cement type on early revision of Charnley total hip prostheses. A review of 8,579 primary arthroplasties from the Norwegian Arthroplasty Register. $J$ Bone Joint Surg Am 1995; 77: 1543-50.

6. Espehaug B, Furnes O, Havelin LI, Engesæter LB, Vollset SE. Cement type and failure of total hip replacements. J Bone Joint Surg Br 2002; 84: 832-8.

7. Espehaug B, Engesæter LB, Vollset SE, Havelin LI, Langeland N. Antibiotic prophylaxis in total hip arthroplasty. Review of 10,905 primary cemented total hip replacements reported to the Norwegian Arthroplasty Register, 1987-1995. J Bone Joint Surg Br 1997; 79: 590-5.

8. Engesæter LB, Lie SA, Espehaug B, Furnes O, Vollset SE, Havelin LI. Antibiotic prophylaxis in total hip arthroplasty - Effects of antibiotic prophylaxis systemically and in bone cement on the revision rate of 22,170 primary hip replacements followed 0-14 years in the Norwegian Arthroplasty Register. Acta Orthop Scand 2003; 74 (6): 644-651.

9. Furnes O, Lie SA, Espehaug B, Vollset SE, Engesæter LB, Havelin LI. Hip disease and the prognosis of total hip replacements. A review of 53698 primary total hip replacements reported to the Norwegian Arthroplasty Register 1987-1999. J Bone Joint Surg Br 2001; 83: 579-86.

10. Hansen FH. Sykehussektoren på 1990-tallet. Sterk vekst-stabile fylkesvise forskjeller. Samdata sykehus Rapport 1/00, Trondheim, Unimed NIS Samdata 2000.

11. Lie SA, Havelin LI, Engesæter LB, Gjessing HK, Vollset SE. Mortality after total hip replacement: 0-10 year follow-up of 39,543 patients in the Norwegian Arthroplasty Register. Acta Orthop Scand 2000; 71: 19-27.

12. Lie SA, Engesæter LB, Havelin LI, Furnes O, Vollset SE. Early postoperative mortality after 67,548 total hip replacements. Causes of death and tromboprophylaxis in 68 hospitals in Norway from 1987 to 1999. Acta Orthop Scand 2002; 73: 392-9.

13. Flugsrud GB, Nordsletten L, Espehaug B, Havelin LI, Meyer HE. Risk factors for total hip replacement due to primary osteoarthritis. A cohort study in 50,034 persons. Arthritis Rheum 2002; 46: 675-82.

14. Flugsrud GB, Nordsletten L, Espehaug B, Havelin LI, Meyer HE. Weight change and the risk of total hip replacement. Epidemiology 2003; 14 (5): 578-584.

15. Riksrevisjonens undersøkelse av effektivitet i sykehus - en sammenligning av organiseringen av hofteoperasjoner. 2003-2004; Dokument nr. 3:3. http://www.riksrevisjonen.no/PDF/38372439.pdf.

16. Paavolainen P, Pukkala E, Pulkkinen P, Viduri T. Cancer incidence in Finnish hip replacement patients from 1980 to 1995: A nationwide cohort study involving 31,651 patients. J Arthroplasty 2000; 15 (1): 136-7.

17. Furnes O, Espehaug B, Lie SA, Vollset SE, Engesæter LB, Havelin LI. Early failures among 7174 primary total knee replacements. A follow-up study from The Norwegian Arthroplasty Register 1994-2000. Acta Orthop Scand 2002; 73: 117-29. 
18. Furnes A, Lie SA, Havelin LI, Engesæter LB, Vollset SE. The economic impact of failures in total hip replacement surgery. The Norwegian Arthroplasty Register 1987-1993. Acta Orthop Scand 1996; 67: 115-21.

19. Engesæter LB, Furnes A, Havelin LI, Lie SA, Vollset SE. Hofteregisteret. God samfunnsøkonomi. Tidsskr Nor Logefor 1996; 116: 3025-7.

20. Havelin LI, Furnes O, Espehaug B. Årsrapport Nasjonalt Register for leddproteser Bergen, 2002. www.haukeland.no/nrl.

21. Havelin LI, Espehaug B, Vollset SE, Engesæter LB. Early aseptic loosening of uncemented femoral components in primary total hip replacement. A review based on the Norwegian Arthroplasty Register. J Bone Joint Surg Br 1995; 77: 11-7.

22. Havelin LI, Vollset SE, Engesæter LB. Revision for aseptic loosening of uncemented cups in 4,352 primary total hip prostheses. A report from the Norwegian Arthroplasty Register. Acta Orthop Scand 1995; 66: 494500 .

23. Furnes O, Lie SA, Havelin LI, Vollset SE, Engesæter LB. Exeter and Charnley arthroplasties with Boneloc or high viscosity cement. Comparison of 1127 arthroplasties followed for 5 years in the Norwegian Arthroplasty Register. Acta Orthop Scand 1997; 68: 515-20.

24. Havelin LI, Espehaug B, Lie SA, Engesæter LB, Furnes O, Vollset SE. The Norwegian Arthroplasty Register. 11 years and 73,000 arthroplasties. Acta Orthop Scand 2000; 71: 337-53.

25. Havelin LI, Espehaug B, Engesæter LB. The performance of two hydroxyapatite-coated acetabular cups compared with Charnley cups. From the Norwegian Arthroplasty Register. J Bone Joint Surg Br 2002; 84: 839-45.

26. Espehaug B, Havelin LI, Engesæter LB, Langeland N, Vollset SE. Patient satisfaction and function after primary and revision total hip replacement. Clin Orthop 1998; 351: 135-48.

27. Espehaug B, Havelin LI, Engesæter LB, Langeland N, Vollset SE. Patient-related risk factors for early revision of total hip replacements - a population register-based case-control study. Acta Orthop Scand 1997; 68: 207-15.

28. Espehaug B, Havelin LI, Engesæter LB, Vollset SE. The effect of hospital-type and operating volume on the survival of hip replacements. A review of 39,505 primary total hip replacements reported to the Norwegian Arthroplasty Register, 1988-1996. Acta Orthop Scand 1999; 70: 12-8.

29. Skeide BE, Lie SA, Engesæter LB, Vollset SE. Totalprotese etter fractura colli femoris. Resultater fra Nasjonalt Register for Leddproteser. Tidsskr Nor Lageforen 1996; 116: 1449-51.

30. Espehaug B, Havelin LI, Engesæter LB, Vollset SE, Langeland N. Early revision among 12,179 hip prostheses. A comparison of 10 different prosthesis brands reported to the Norwegian Arthroplasty Register, 19871993. Acta Orthop Scand 1995; 66: 487-93.

31. Bystrøm S, Espehaug B, Furnes O, Havelin LI. Femoral head size is a risk factor for total hip luxation - A study of 42,987 primary hip arthroplasties from the Norwegian Arthroplasty Register. Acta Orthop Scand 2003; 74 (5): 514-24.

32. Furnes O, Havelin LI, Espehaug B, Engesæter LB, Lie SA, Vollset SE. Det norske leddproteseregisteret - 15 nyttige år for pasientene og for helsevesenet. Tidsskr Nor Laegeforen 2003; 123 (10): 1367-9. 